\title{
Design and Synthesis of Multi-Mode Bandpass Filter for Wireless Applications
}

\author{
Satheeshkumar Palanisamy ${ }^{1, *(\mathbb{C})}$, Balakumaran Thangaraju ${ }^{1}\left(\mathbb{D}\right.$, Osamah Ibrahim Khalaf $^{2}$, Youseef Alotaibi ${ }^{3}(\mathbb{D}$ \\ and Saleh Alghamdi ${ }^{4}$ \\ 1 Department of ECE, Coimbatore Institute of Technology, Coimbatore 641014, India; balakumaran@cit.edu.in \\ 2 Al-Nahrain Nano-Renewable Energy Research Center, Al-Nahrain University, Baghdad 10072, Iraq; \\ usama.ibrahem@coie-nahrain.edu.iq \\ 3 Department of Computer Science, College of Computer and Information Systems, Umm Al-Qura University, \\ Makkah 21955, Saudi Arabia; yaotaibi@uqu.edu.sa \\ 4 Department of Information Technology, College of Computers and Information Technology, Taif University, \\ Taif 21944, Saudi Arabia; s.algamedi@tu.edu.sa \\ * Correspondence: satheeshkumar.p@cit.edu.in
}

check for updates

Citation: Palanisamy, S.; Thangaraju,

B.; Khalaf, O.I.; Alotaibi, Y.;

Alghamdi, S. Design and Synthesis of Multi-Mode Bandpass Filter for Wireless Applications. Electronics 2021, 10, 2853. https://doi.org/ 10.3390 /electronics10222853

Academic Editor: Leonardo Lizzi

Received: 13 October 2021

Accepted: 16 November 2021

Published: 19 November 2021

Publisher's Note: MDPI stays neutral with regard to jurisdictional claims in published maps and institutional affiliations.

Copyright: (c) 2021 by the authors. Licensee MDPI, Basel, Switzerland. This article is an open access article distributed under the terms and conditions of the Creative Commons Attribution (CC BY) license (https:/ / creativecommons.org/licenses/by/ $4.0 /)$.

\begin{abstract}
In this paper, a compact bandpass filter with improved band stop and band pass characteristics for wireless applications is built with four internal conductive poles in a single resonating cavity, which adds novel quad-resonating modes to the realization of band pass filter. This paper covers the design and testing of the S-band combline coaxial cavity filter which is beneficial in efficient filtering functions in wireless communication system design. The metallic cavity high $\mathrm{Q}$ coaxial resonators have the advantages of narrowband, low loss, better selectivity and high potential for power handling, as compared to microstrip filter in the application to determine the quality factor of motor oils. Furthermore, the tuning of coupling screws in the combline filter allows in frequency and bandwidth adjustments. An impedance bandwidth of $500 \mathrm{MHz}$ (fractional bandwidth of $12.8 \%$ ) has been achieved with an insertion loss of less than $2.5 \mathrm{~dB}$ and return loss of $18 \mathrm{~dB}$ at the resonant frequency. Four-pole resonating cavity filters have been developed with the center frequency of $4.5 \mathrm{GHz}$. Insert loss at $0 \mathrm{~dB}$ and estimated bandwidth at $850 \mathrm{MHz}$ and a quality factor of 4.3 for the band pass frequencies between 4 and $8 \mathrm{GHz}$ is seen in the simulated result.
\end{abstract}

Keywords: band pass filter; quadruple-mode; insertion loss; iris structure; unloaded Q-factor; duplexer; diplexer

\section{Introduction}

In signal processing, filter is a device, that processes frequency-dependent way of signals. The size of a filter is usually determined by resonators, which are fundamental elements in a filter [1,2]. Reducing the dimensions of the resonator is a better way to reduce the size of the filter. In most cases, to reduce the resonator size, two approaches are used. Changing the physical structures $[3,4]$ is one of the strategy, another approach is to change the traditional resonator to produce additional modes that will make the resonator work as a multimode resonator. As a result, one physical resonator can be modelled as a series of electrical resonators [5].

Furthermore, multiple filters at various stages are present in a single transceiver. Some of them require minimal losses, especially when it is positioned at the front end of the receiver [6]. In this situation, for achieving better Q-factors, waveguide technology is used. Unfortunately, waveguides are bulky and lead to the usage of heavy components. Therefore, substantial efforts have been made to alleviate this problem.

Using a modified coaxial cavity resonator with four connected conductive posts, a unique quad-mode band pass filter is proposed in this study. Conventional designs need for a coupling window to control coupling between the inner posts. To maximize space 
utilization and achieve a high factor, no metallic walls are required to enclose the hollow in the suggested filter. Compared to typical coaxial filters, the suggested filter structure allows for a more compact construction while improving the resonator unloaded Q. It is also possible to modify inductive or capacitive sequential and cross-coupling which is thank to the cavity's variable mix of electric and magnetic coupling.

Consequently, numerous controllable transmission zeros with variable passband characteristics can be easily realized. Although multimode filters have benefits such as low insertion loss and smaller size, designing a higher order multimode filter is difficult due to its design complexity of the coupling with the degenerated modes in a single multimode resonator. Literature shows that there are many papers describing a single multimode resonator, but only a few papers focusing on manifold multimode filters or resonators $[7,8]$. It is also difficult to build a multimode resonator filter with a broad stopband because their parasitic resonances or modes and multiple degenerate modes operates nearer to the fundamental mode $[9,10]$. The stated stopband bandwidth is insufficient to reject anything beyond the third parasitic spurious harmonics.

In this paper, an efficient method for designing high order multimode filters is used. The proposed method aids in achieving effective multimode operation with an ultra-wide stopband at the same time.

The remaining of this paper is organized as following: Section 2 presents the related works. Section 3 presents the proposed combline filter structure. Section 4 presents the results and discussions and Section 5 outlines the conclusion.

\section{Related Works}

The quad mode bandpass filter, is equivalent to a parallel-tuned circuit and most frequently used with or without amplification for general transmitter sharpening of a single front end receiver selectivity. In order to accommodate the rapid development of mobile communication systems, the requirements for efficient improvement and size reduction have become increasingly stringent. Dielectric loading [11], dual and multimode techniques [12] can meet filter size and performance requirements. However, the majority of these waveguide-based methods are not practically realistic to coaxial cavity combline structures filters, which are favored in base-stations. Although they have a high power capability and a very high selectivity (Q-factor), combline structure based coaxial cavity filters are widely used in telecommunication sectors for many years [13]. They are widely used, particularly in wireless base-station applications, due to their advantages of compact size, relatively high-factor, and low production cost $[9,10]$.

Since the 1980s, a large number of studies on the analysis and design of coaxial cavity filters have been carried out [11-15]. In recent years, most researchers, have centered on the filter coupling topology for improving stopband characteristics with a reduced resonator count [16-18]. Some researchers realized an adjustable stop band at a specific frequency by preselecting and/or presetting a distinct inductive and capacitive coupling between two coaxial resonators, one instantly following the other on a signal path. More as of late, a few investigations consider with respect to the compact combline coaxial cavity bandpass filters have been focused. By investigating controllable blended electric and magnetic coupling, a combline coaxial cavity filter with a diminished resonator count and filter dimensions was presented [19]. By modifying the focusing angle of a few of its coaxial depth resonators, the longitudinal length of the filter can be decreased to a certain degree, and different tolerable transmission zeros can be produced due to the nearness of cross-coupling across the longer distance resonators [20]. In any case, the size-reduced bandpass channels based on the coaxial depth resonator and the joint channel topology have once in a while been detailed.

The resonance characteristics of the proposed compact coaxial quad-mode filter shows a high Q-factor. The filter can be designed for a specification with the adequate dimensions. The filter size is small and the bandwidth is less than 1\% [21,22]. For broader bandwidths, resonator coupling is compact and are closely spaced. Coaxial cavity resonating filter is widely used in communication and radar systems with the advent of microwave com- 
munications. The filter can be defined by the cavity structure as a standard filter and a coaxial square cavity filter. The high $\mathrm{Q}$ value feature of the coaxial cavity filter is easy to physically understand and is applicable to the low insertion loss, narrow band and great suppression of sidebands. Using the proposed concept, four and eight-pole bandpass filters are equipped with various filtering functions. Combline cavity filters are available in single, double, and triple mode bandpass configurations. In satellite communications, four-pole or six-pole double (dual) mode filters are commonly used in output multiplexers, and eight-pole double mode filters are commonly used in input multiplexers. Output multiplexers have at least two or three cascaded waveguide cavities, while input multiplexers have at least four cascaded waveguide cavities [23-27].

Any weight or volume savings achieved in satellite communications are extremely important $[28,29]$. Nowadays, filters used for multiplexers are heavier and bulky one than filters designed in accordance with current development. Furthermore, it is known that two or three triple mode cavities can be used as a six-pole filter in the output multiplexer. Tragically, this sort of six-pole filter can be propelled onto a multiple input lines of the multiplexer at a sidewall of the triple (multi) mode cavities [30-32]. This side-wall propelling can be much larger than an end-wall propelling. If a filter has been made to create more number of transmission zeros, then the response of that filter can be improved. With past filters, the maximum quantity of transmission zeros that can be delivered is rise to the arrange of the channel minus two. A six-pole earlier art decides dual mode filter can be made to generate four transmission zeros, and such a filter produces an elliptic function response.

A bandpass filter with exactly one more four mode cavity along with coupling and tuning screws in the filter resonates at its resonant frequency in four different independent orthogonal radiating modes at the same time. Any additional cavities with four mode coupling cavity are adjacent to each other. Any immediate adjacent cavities can be coupled to one another and resonates at their resonant frequency, with an input and output [33].

The filter of the present invention preferably has at least two cavities, one of which is a quadruple mode cavity and the other of which is either a single mode cavity, a dual mode cavity, a triple mode cavity, or a quadruple mode cavity. Even better, the present invention's filter is operated in such a way that the number of transmission zeros equals the order of the filter. Preferably, to a filter with at least one cavity resonating in four independent orthogonal modes at the same time. Resonating coaxial cavity, consisting of four conductive couplings. Rather than using couplings, coupling windows, can be used to accomplish sufficient control between the inner posts [34].

The proposed filter maximizes the metallic walls within the cavity. The use of space, achieves an optimal filter. The suggested filter configuration enables compact configuration with a resonator enhancement. Furthermore, because of the controllable electric and magnetic combination, the dominant sequential (inline) coupling, in the cavity is required to change cross-coupling to inductive or capacitive effect in the range of $40 \mathrm{MHz}$ to $960 \mathrm{MHz}$ spectrum ranges. A high quality factor, $Q$, improved efficiency with better stability and narrowly spaced (up to $75 \mathrm{kHz}$ ) frequencies is attained [35]. To increase the internal capacity of the resonating filter cavities, physical dimensions of traditional cavity filters can be varied. It ranges from 85 in the $40 \mathrm{MHz}$ range to less than 11 in the $40 \mathrm{MHz}$ range. The cavity filters become more realistic in the range of $900 \mathrm{MHz}$, where Q-factor is substantially higher than the resonators and filters for the lumped part [36].

\section{Proposed Filter Structure}

The novelty of this paper is to build a compact bandpass filter with improved stop band and bandpass characteristics with four internal conductive poles in a single resonating cavity, which adds novel quad-resonating modes. This proposed concept is used to design, manufacture, and test four- and eight-pole bandpass filters with various filtering functions. The measured results predict that an excellent factor can be obtained while maintaining a small size. Normally, the proposed coaxial cavity filter (resonator) design concept can provide an unloaded filter characteristics improvement of approximately $15 \%$ for a 
given volume. This means that a volume savings of $30 \%$ to $35 \%$ can be achieved while maintaining a comparable factor value with conventional coaxial models. It should be noted that a similar resonator configuration based on the substrate integrated waveguide (SIW) technique was reported in [21]. However, only the first three resonant modes are used to design the dual-band filter, with the last mode considered spurious due to the lack of multiple transmission zero investigations. A standard combline filter is the basic filter structure, with a number of resonators situated between two ground planes in a straight line [6] and its equivalent circuit is as shown in Figure 1. In the equivalent circuit, LC shunt and series combination depicts a bandpass type filter to select the desired band of frequencies.

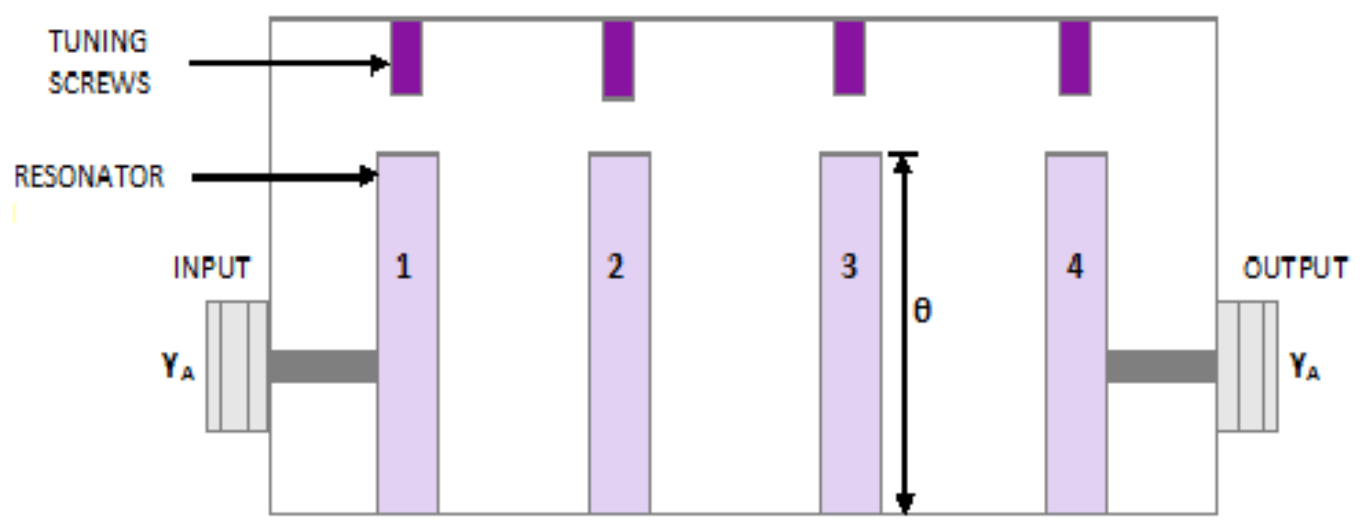

(a)

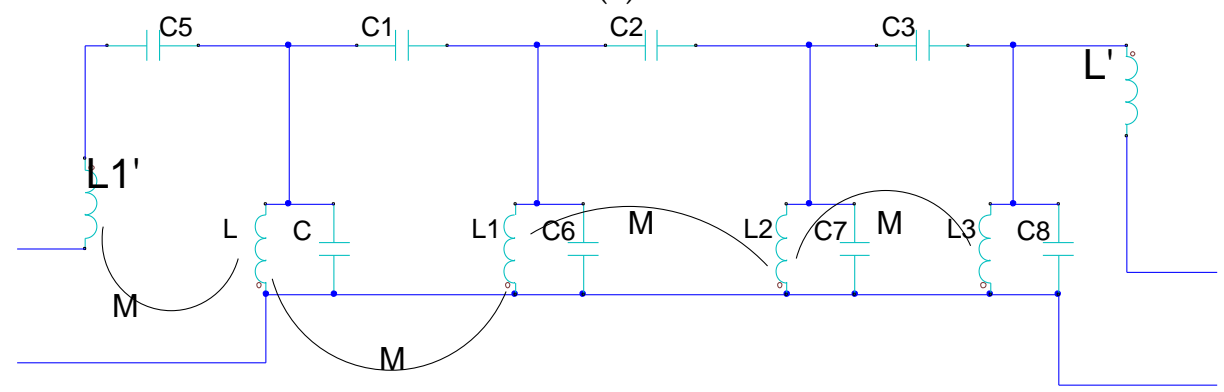

(b)

Figure 1. (a) General combline cavity filter and (b) Combline filter-equivalent circuit model.

\section{Quadruple-Mode Resonator}

Four pole bandpass filters with various filtering functions are constructed using this suggested definition. The calculated results indicate that, with a compact scale, an outstanding element can be achieved [12]. As shown in Figure 1, coupling between neighbouring resonators is performed by the use of a coupling window, which is regulated by the size of the window and/or a coupling screw piercing into the cavity from the top cover. Transmission zeros are frequently introduced into the stopband in order to increase filter selectivity by cross-coupling across non-adjacent resonators.

\section{Proposed Configurations and Characteristics}

The physical setup of the quad-mode resonator that has been implemented, consisting of four different inner conductive poles within a single resonating cavity. Its side dimensions include length and height define the size of the square cavity. The mathematical formulations for the normalized capacitances per unit element, between resonators and ground for combline filter [7], are given in Equations (1)-(5). The physical configuration of the proposed quad resonator, which consists of four shaped inner conductor poles in a single cavity, is seen in Figure 2. On the bottom of the metallic housing, all four of the inner posts are short-circuited and open-circuited at the other end. Figure 2 and Table 1 
also show the key dimensions characteristics. The side length $\mathrm{L}$ and height $\mathrm{H}$ of the square cavity describe its dimensions. The cavity corner is filled with round $\mathrm{R}$, and $\mathrm{d}$ represents the distance between the post centre and the cavity centre. The radius and height of each post are denoted by $\mathrm{r}$ and $\mathrm{h}$, respectively. Instead of the traditional coaxial resonator plugs, the internal poles are folded $90^{\circ}$ and extended towards the center of the cavity to improve the electric connection between them. $T$ and $\mathrm{L}$ are the thickness and length of the bended portion (hence referred to as the head). To refine the electrical connector, both sides of each pole are chamfered with $\mathrm{c}$ at the open end. The total distance between the centre of the cavity and the open edge of the head is shown by g, so that the distance between two diagonal posts is $2 \mathrm{~g}$. More specifically, Figure 2 shows a four-pole second elliptical filter with Cavity 4, resonates at its resonance frequency in four distinct orthogonal modes at the same time. In Cavity $4, \mathrm{TE}_{113}$ mode, $\mathrm{TM}_{110}$ mode, $\mathrm{TM}_{110}$ mode, and $\mathrm{TE}_{113}$ modes are made to resonate successively. Electromagnetic energy is introduced into Cavity 4 through the input coupling Probe 6, resulting in the activation of the first $\mathrm{TE}_{113}$ mode's electric field. Coupling Screw 8 is responsible for transferring energy from the first $\mathrm{TE}_{113}$ mode to the second $\mathrm{TM}_{110}$ mode. Through Coupling Screws 10 and 12, energy is transmitted to the second $\mathrm{TM}_{110}$ mode, then to the third $\mathrm{TM}_{110}$ mode and finally to the fourth $\mathrm{TE}_{113}$ mode. $\mathrm{A}$ magnetic field transfer via Iris 16's Aperture 14 couples energy out of the Cavity 4.

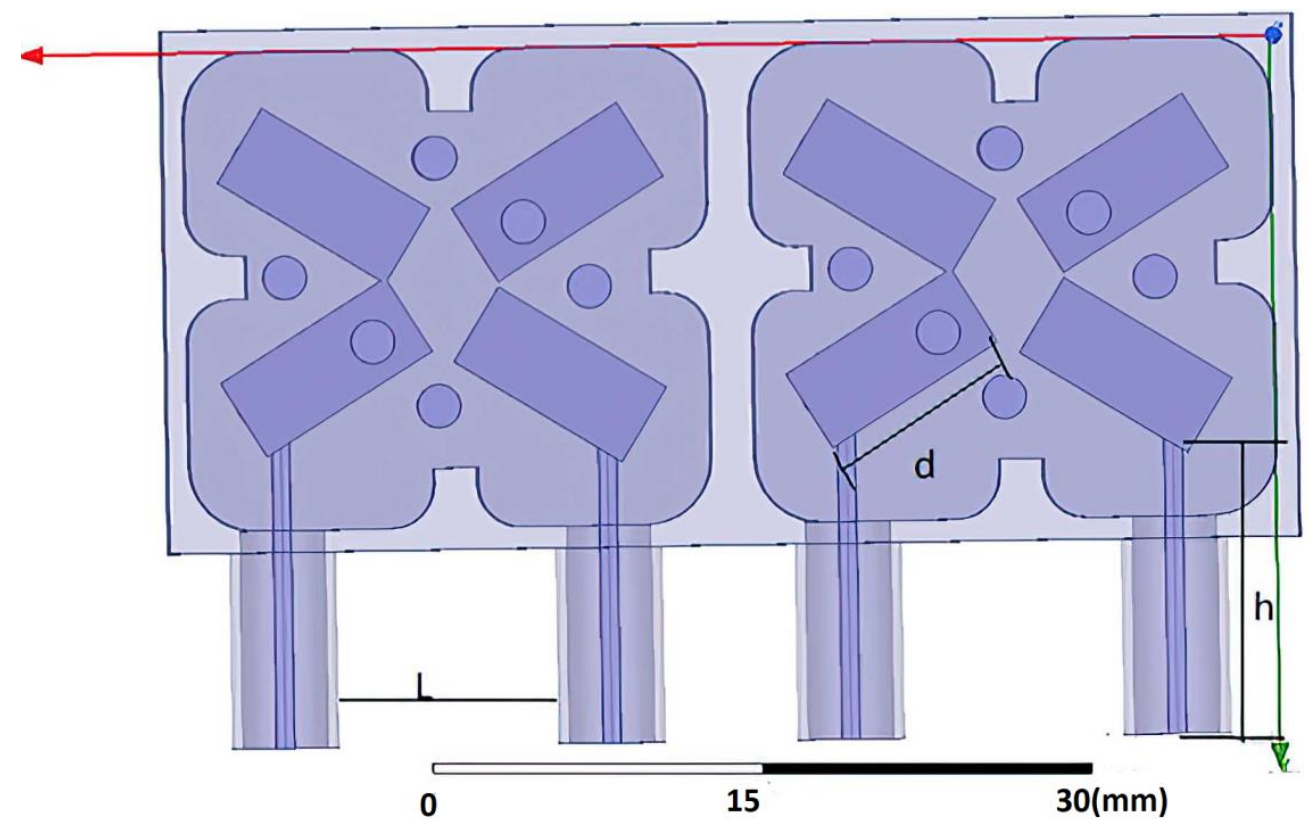

Figure 2. Four-pole quad-mode resonator with proposed dimensions.

Table 1. Dimensional parameters of four-pole quad-mode resonator.

\begin{tabular}{ccccc}
\hline $\mathbf{a}$ & $\mathbf{L}$ & $\mathbf{h}$ & $\mathbf{r}$ & $\mathbf{d}$ \\
\hline $33 \mathrm{~mm}$ & $15 \mathrm{~mm}$ & $18 \mathrm{~mm}$ & $3 \mathrm{~mm}$ & $10 \mathrm{~mm}$ \\
\hline
\end{tabular}

A filter built in accordance with this invention might contain at least two cavities, one of which resonates at its resonant frequency in four separate orthogonal modes at the same time, and therefore, the other of which is either one, dual, triple, or quadruple mode cavity. Likewise, a two-cavity combline filter built in accordance with the present invention could have a quadrature mode cavity in addition to a single, dual, triple, or quadruple mode cavity. A coupling screw may be added in each of these quadruple mode cavities to provide a negative feedback coupling between a first mode and a fourth mode, resulting in two transmissible zeroes. When the filter contains more than two quadruple mode cavity, a negative feedback coupling forms between the first and fourth modes of each cavity. When each cavity resonates at its resonance frequency in four separate orthogonal modes at the 
same time in a two-cavity filter, for example, the negative feedback coupling in the first cavity is M14 and M58 in the second cavity. In other words, the fifth mode matches the first mode, and the eighth mode matches the fourth mode of the second cavity.

New resonant modes are revealed by this innovative post arrangement. The electromagnetic (EM) full-wave simulator ANSYS HFSS (eigenmode) [22] is used for simulation. The suggested coaxial resonator generates four distinct resonant: (a) fundamental, (b) differential, and (c and d) a pair of orthogonal degenerate modes. The resonant modes are studied in the following explanation using basic thoughts on the orientation of their electric and magnetic fields, but the same results may be drawn by considering the electric fields as well. The magnetic field looping around all four posts has the same direction for the basic mode (named Mode 1). As a result, it creates a huge magnetic field loop in the designed cavity while appearing to have only one conductive post at the cavity centre. In the differential mode (also known as Mode 2), the magnetic field orientations circulating around the four inner conductive posts diverge from one another. As a result, it seems to be four tiny independently resonated cavities, similar to a normal coaxial resonator with inner metallic walls. Both degenerative modes ( 3 and 4 ) are orthogonal in space. The magnetic field only focuses in the volume surrounding two diagonal posts for each one, resulting in the fulfillment of the boundary condition.

Accordingly, the resonance frequency of each mode is governed not only by the dimensions of the column and cavity, but also by the position of the column, which is primarily determined by the parameter. Consider a square cavity with dimensions of $\mathrm{a}=33 \mathrm{~mm}, \mathrm{H}=17 \mathrm{~mm}$, and $\mathrm{R}=3 \mathrm{~mm}$. The aforementioned cavity dimensions remain constant for all four-pole resonators and filters described below. The inner post's additional dimensions are as follows: $\mathrm{r}=2.3 \mathrm{~mm}, \mathrm{~h}=14.9 \mathrm{~mm}, \mathrm{~L}=11 \mathrm{~mm}, \mathrm{~T}=3 \mathrm{~mm}, \mathrm{c}=1.5 \mathrm{~mm}$ and $\mathrm{g}=2.3 \mathrm{~mm}$ as shown in Figure 3. The corner of the cavity has a round $\mathrm{R}$ fillet. On each post of its side edges of each post are chamfered at the open end for the fine tuning of electric wave coupling. The spacing distance between two diagonal posts and distance between cavity center and open edge of head is one unit length.

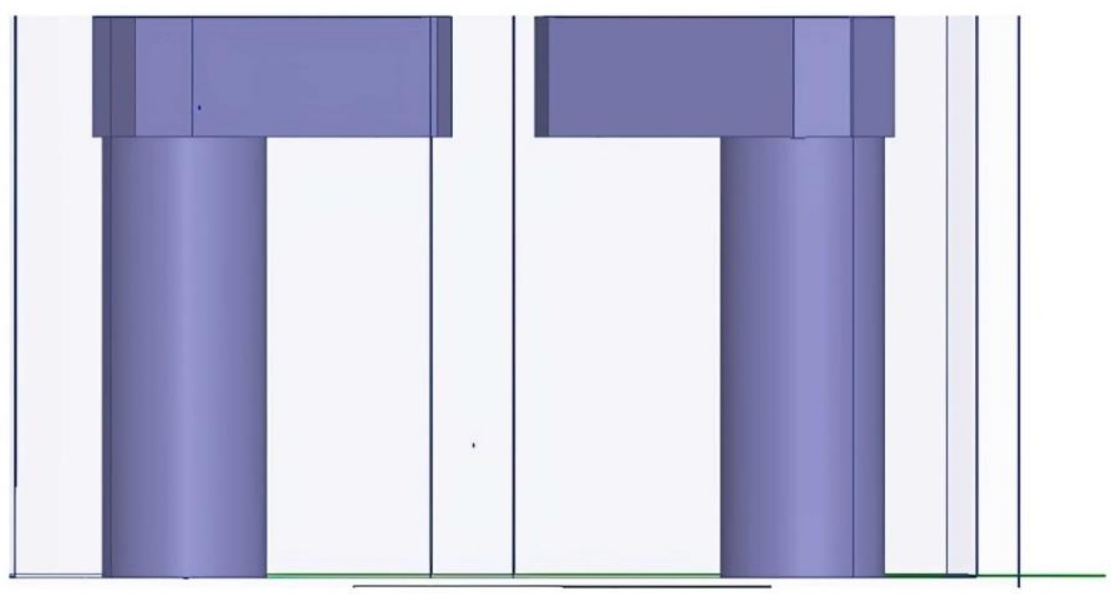

Figure 3. Projected quad-mode resonator with proposed dimensions (side view).

Let us consider a square cavity, the cavity dimensions is same for subsequent four-pole filters and the quadruple-mode resonators as shown in Figures 4 and 5 . The dimensions of the inner poles are as follows: $R=3 \mathrm{~mm}, \mathrm{~L}=9 \mathrm{~mm}, \mathrm{r}=2 \mathrm{~mm}, \mathrm{c}=1 \mathrm{~mm}$. 


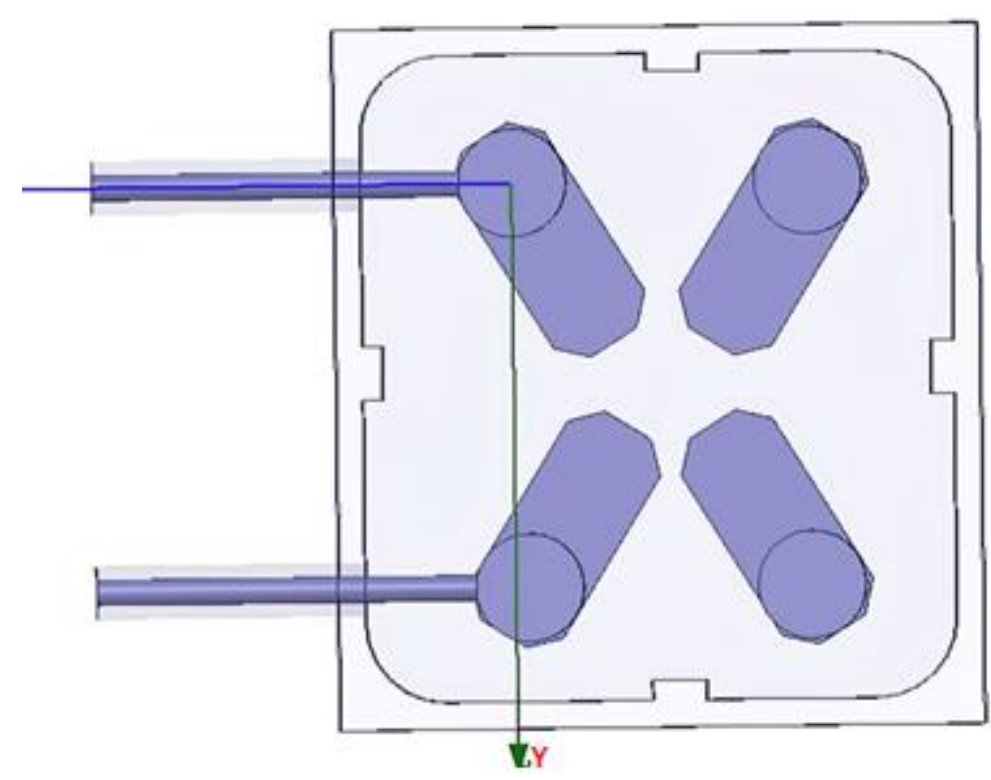

Figure 4. Proposed dimension of quadruple-mode resonator (top view).

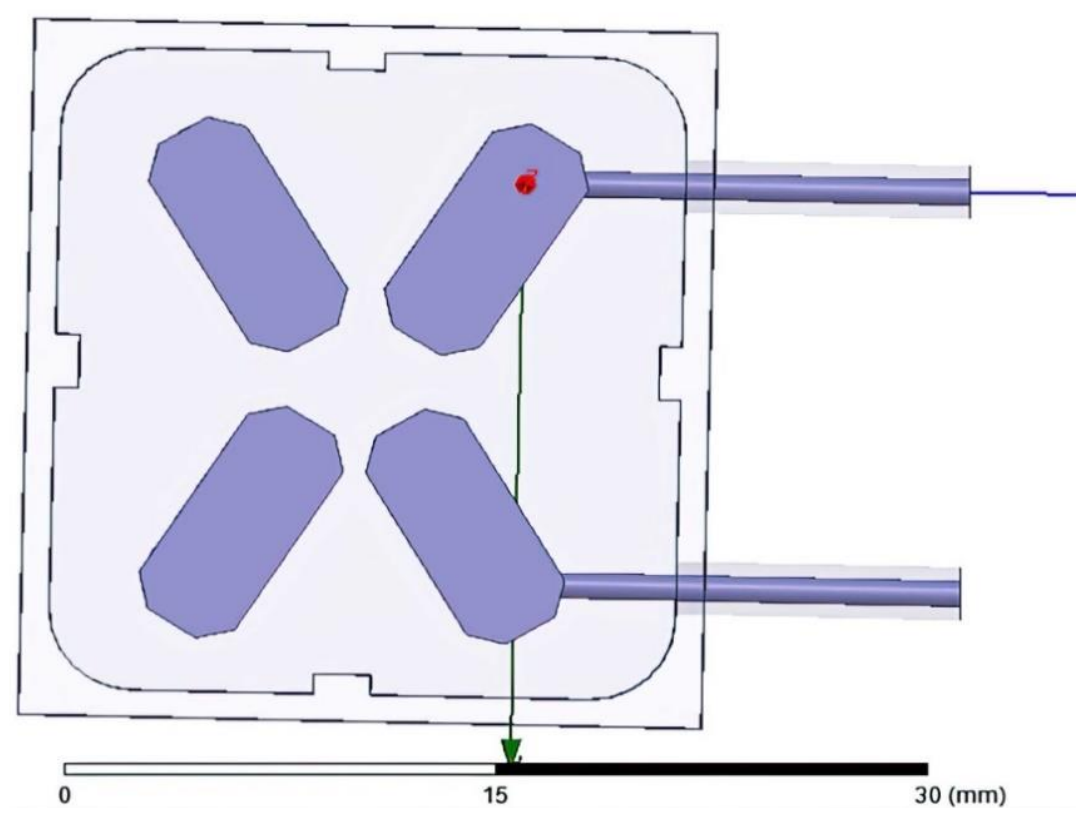

Figure 5. Perspective view of the cascaded coaxial quadruplet filter (top view).

The cascaded pair of degenerate orthogonal modes created in the coaxial resonator is designed. The four inner posts are placed in a single cavity, its equivalent circuit for resonant space will differ according to the resonating mode, and it is possible to satisfy the boundary condition of the post location. The resonating frequency of each mode is therefore defined by the cavity dimensions of the post and cavity and is primarily correlated with the parameter.

\section{Cavity Filter Design}

Resonating modes are chosen based on the pass-band spectrum, coupling structure, response modulation frequency tuning, band stop/pass-band tuning, and standing wave modulation are fully taken for consideration. The measurement of the eigen mode resonant unit is selected on the basis of the filter's pass-band. The single cavity is designed having the same size as the mode. By using the eigen mode solver created on the Euclidean finite element algorithm. In the frequency range of $30 \mathrm{MHz}$ to $40 \mathrm{GHz}$ and with bandwidth 
choices from less than $0.5 \%$ to over $66 \%$, cavity filter designs are available [36]. Cavity filters provides the consumer with very low loss of insertion, steep skirt selectivity, and narrower bandwidths than discrete filters of components. The efficiency of the cavity filter is dependent on the selection of components and the physical configuration of the helical coils, resonators, and the shape and size of the cavity housing. Using aluminum as the base metal, standard cavity filters are typically constructed.

\section{Normalized Capacitance between Resonators and Ground}

This section presents the capacitances needed for the calculation of resonator ' $d$ '. The resonator is first thought to be rectangular and then transformed into a cylindrical structure with a diameter of ' $d$ '. The width ' $w$ ', length ' $L$ ', and thickness ' $t$ ' are the rectangular resonator. The resonator impedance is taken as $70 \mathrm{ohm}$ in order to achieve a high unloaded ' $Q$ ' for filter. Mathematical formulations are given in Equations (1)-(6) for the standardized capacitances per unit element between resonators and ground for combline filter [7].

$$
\begin{aligned}
& \frac{\mathrm{C}_{0}}{\varepsilon}=\frac{376.7 \mathrm{Y}_{\mathrm{A}}}{\sqrt{\varepsilon_{\mathrm{r}}}}\left(1-\sqrt{\frac{\mathrm{G}_{\mathrm{T} 1}}{\mathrm{Y}_{\mathrm{A}}}}\right) \\
& \frac{C_{n}}{\varepsilon}=\frac{376.7 Y_{A}}{\sqrt{\varepsilon_{\mathrm{r}}}}\left[\frac{Y_{\text {an }}}{Y_{A}}-1+\frac{\mathrm{G}_{\text {Tn }}}{Y_{A}}-\frac{J_{n-1, n}}{Y_{A}} \tan \theta_{0}\right]+\frac{C_{n+1}}{\varepsilon} \\
& \frac{\mathrm{C}_{\mathrm{n}+1}}{\varepsilon}=\frac{376.7 \mathrm{Y}_{\mathrm{A}}}{\sqrt{\varepsilon_{\mathrm{r}}}}\left(1-\sqrt{\frac{\mathrm{G}_{\mathrm{Tn}}}{\mathrm{Y}_{\mathrm{A}}}}\right) \\
& \frac{\mathrm{C}_{01}}{\varepsilon}=\frac{376.7 \mathrm{Y}_{\mathrm{A}}}{\sqrt{\varepsilon_{\mathrm{r}}}}-\frac{\mathrm{C}_{0}}{\varepsilon} \\
& \left.\frac{\mathrm{C}_{\mathrm{j}, \mathrm{j}+1}}{\varepsilon}\right|_{\mathrm{j}=1 \text { to } n-1}=\left(\frac{376.7 \mathrm{Y}_{\mathrm{A}}}{\sqrt{\varepsilon_{\mathrm{r}}}}\right)\left(\frac{\mathrm{J}_{\mathrm{j}, \mathrm{j}+1}}{\mathrm{Y}_{\mathrm{A}}}\right) \tan \theta_{0} \\
& \frac{\mathrm{C}_{\mathrm{n}, \mathrm{n}+1}}{\varepsilon}=\frac{376.7 \mathrm{Y}_{\mathrm{A}}}{\sqrt{\varepsilon_{\mathrm{r}}}}-\frac{\mathrm{C}_{\mathrm{n}+1}}{\varepsilon}
\end{aligned}
$$

where, $\varepsilon$ is the permittivity, $\varepsilon_{\mathrm{r}}=1$, ' $\mathrm{n}$ '-order of filter, $\mathrm{Y}_{\mathrm{aj}}$ is the resonator admittance $=1 / 70$, $\mathrm{Y}_{\mathrm{A}}=1 / 50$ and $\theta_{0}=45^{\circ}$ for $\lambda / 8$ resonators. All the mathematical calculations for normalized capacitances are done using SCILAB 6.1.1 (ESI Group, Rungis, France) generated codes.

\section{Physical Filter Dimensions}

In this work, the cavity width selected for the design is $\mathrm{b}=16 \mathrm{~mm} . \Delta \mathrm{C} / \varepsilon[7]$, for $\mathrm{t} / \mathrm{b}=0.4$, where $\Delta \mathrm{C} / \varepsilon=\mathrm{C}_{\mathrm{j}, \mathrm{j}+1} / \varepsilon$, derived in Equation (7) gives the normalized width ' $\mathrm{w}_{\mathrm{j}}$ ' [8] of rectangular resonators.

$$
\left.\frac{W_{j}}{b}\right|_{j=1 \text { to } n}=\frac{1}{2}\left(1-\frac{t}{b}\right)\left[\frac{1}{2} \frac{C_{j}}{\varepsilon}-\frac{\left(C_{f e}^{\prime}\right)_{j-1, j}}{\varepsilon}-\frac{\left(C_{f e}^{\prime}\right)_{j, j+1}}{\varepsilon}\right]
$$

where, $\frac{\mathrm{C}_{\text {fe }}^{\prime}}{\varepsilon}$ is the normalized even-mode fringing capacitance. By equating the diameter of both types of resonators, as shown in Equation (8), the rectangular cavity resonators are converted to cylindrical ones.

$$
\prod \mathrm{d}_{\mathrm{j}}=2\left(\mathrm{~W}_{\mathrm{j}}+\mathrm{t}\right)
$$

The diameter of each resonator is set equal to the average diameter value given by Equation (9) for the simplicity and symmetry of the physical structure.

$$
d=\sum_{j=1}^{n} \frac{d_{j}}{n}
$$


Hole ' $\mathrm{d}_{1}$ ' is drilled into a resonator creating a coaxial structure with a diameter ' $\mathrm{D}$ ' tuning screw inserted into this hole. Using the coaxial capacitance formula given in Equation (10), the values of ' $d_{1}$ ' and ' $W$ ' are computed.

$$
\mathrm{C}_{\mathrm{r}}=\mathrm{W} \times 0.02414 \times \frac{\varepsilon_{\mathrm{r}}}{\log \left(\frac{\mathrm{d}_{1}}{\mathrm{D}}\right)} \mathrm{pF}
$$

Using the distributed capacitance ' $\mathrm{Cr}$ ' built at the free end of resonators, the resonators are tuned to resonate. The capacitance $\mathrm{Cr}$ Equation (11) is as follows:

$$
\mathrm{C}_{\mathrm{r}}=\left(\mathrm{Y}_{\mathrm{A}}\right)\left(\frac{\mathrm{Y}_{\mathrm{aj}}}{\mathrm{Y}_{\mathrm{A}}}\right)\left(\frac{\cot \theta_{0}}{\omega_{0}}\right)
$$

where, $\varepsilon$ is the permittivity, $\varepsilon=1$, ' $n$ ' is the order of filter, $Y_{a j}$ is the resonator admittance $(1 / 70)$ and $\mathrm{Y}_{\mathrm{A}}=\frac{1}{50}$. The factors $\frac{\mathrm{G}_{\mathrm{T}}}{\mathrm{Y}_{\mathrm{A}}}$ and $\frac{\mathrm{J}_{\mathrm{j},+1}}{\mathrm{Y}_{\mathrm{A}}}$ are calculated. Where, $\frac{\mathrm{b}}{\mathrm{Y}_{\mathrm{A}}}=0.918$ for $\lambda / 8$ resonators [8], with impedance equal to $70 \Omega$. Filter housings are silver plated for enhanced electrical characteristics and current flow, as most raw metals are inherently loss. To minimize frequency drift over temperature, brass, copper, aluminum or bi-metal resonators are used. The basic circuitry of cavity and duplexer filters are highly tuned resonance circuits that can pass through only certain frequencies. A cavity filter is a resonator at the input and output inside a conducting 'box' with resonating coupling loops. The frequency ranges widely used is from $40 \mathrm{MHz}$ to $960 \mathrm{MHz}$. A better Q quality factor is obtained by increasing the stability efficiency at closely spaced frequencies (down to $75 \mathrm{kHz}$ ) and increasing the internal filter cavity length. Filters based on cavity resonators, in comparison to filters built on lumped-passive element LC resonators or planar cavity resonators, has better power handling capability and better insertion loss. It is popular to use cavity resonator filters in wireless and satellite applications.

\section{Coaxial Resonator Cavity Filters}

The volume of a coaxial resonator is achieved by adjusting its internal and external drivers by taking into account the discharged $Q$ factor and power capability of a coaxial resonator as shown in Figure 6. In short the coaxial resonator cavity filter has many advantages, such as a smaller length and a slimmer band-pass, higher slopes and greater power capacity that are characteristic of Chebyshev's general function.

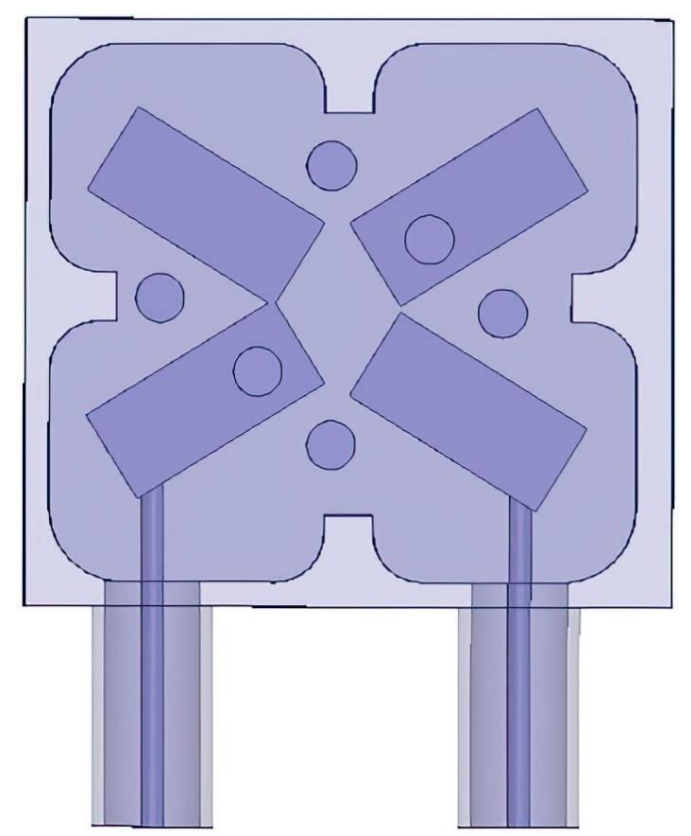

Figure 6. Design of the proposed quad-mode band pass filter (top view). 
Tuning screws placed in the resonant cavities, which can be adjusted externally to the waveguide, provides fine tuning of the resonant frequency by adding more or less thread to the waveguide. Tuning screws in each cavity are sealed with jam nuts and thread-locking compounds. The equivalent circuit is a shutter condenser with a value rising as the screw is inserted for screws inserted at just a small distance as shown in Figures 7 and 8 .

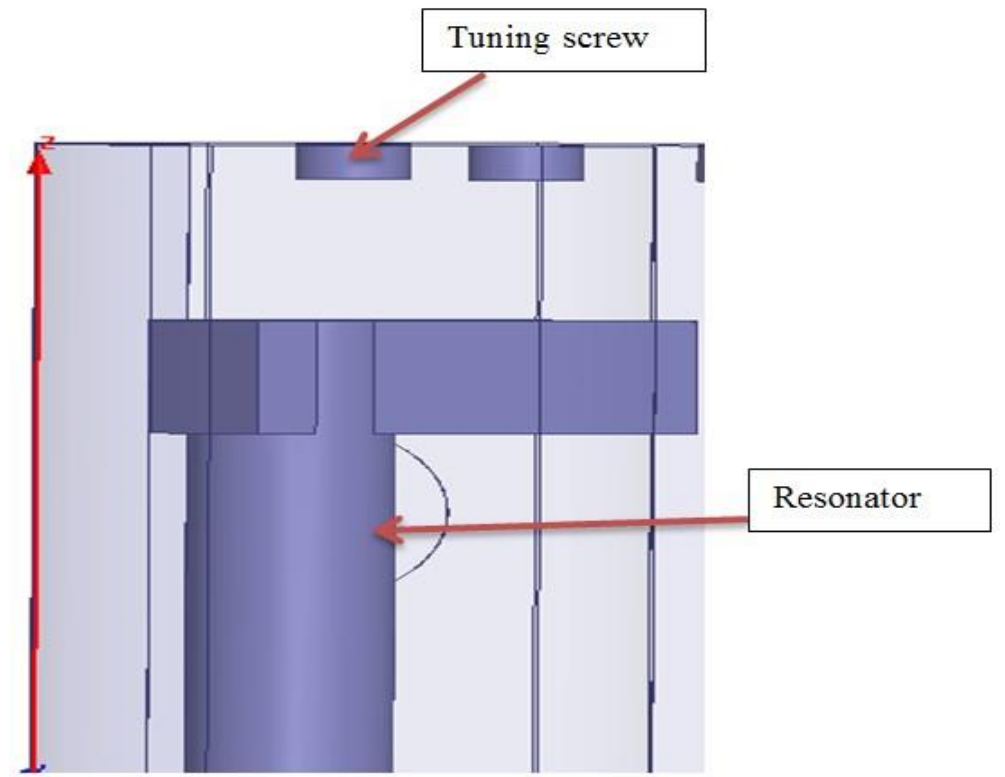

Figure 7. Conventional coaxial resonator (cross-section view).

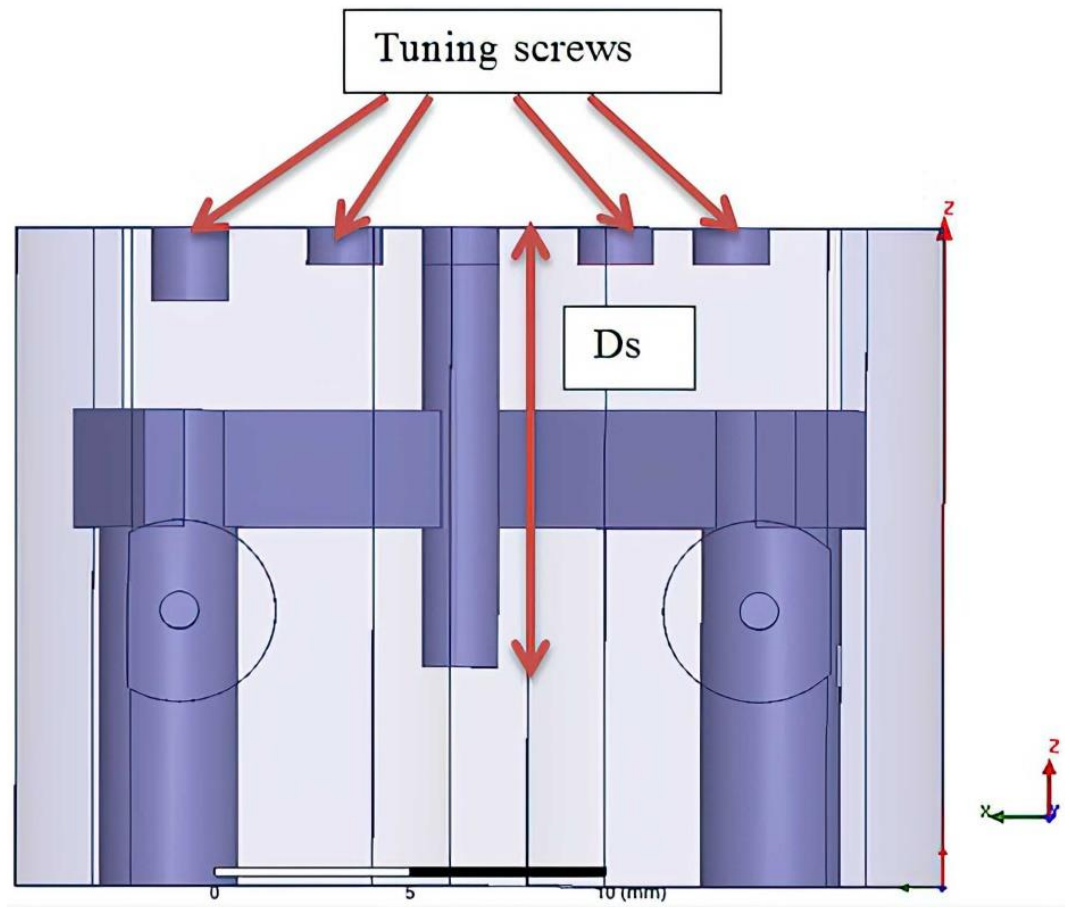

Figure 8. Penetration depth of coupling screw.

The screw has been inserted at a distance of $\lambda / 4$ which is equal to a sequence of LC circuits. Inserting it further allows the impedance to change from capacitive to inductive, i.e., the arithmetic sign shifts. Elliptic characteristic responses receive numerous with the aid of using cross-couplings among non-adjoining cavities and the symptoms of those couplings are decided with the aid of using the orientations of the tuning screws relative to each other. 
Consider two separate size fusion resonators with the same resonator rods magnetically coupled with an iris in the wall. The tuner height of each other does not, therefore, create a synchronous resonance. Figure 9 shows proposed quadruple-mode band pass filter including tap feeders. Figure 10 shows design model of eight-pole bandpass resonating cavity filter by cascading two quadruple-mode resonators.

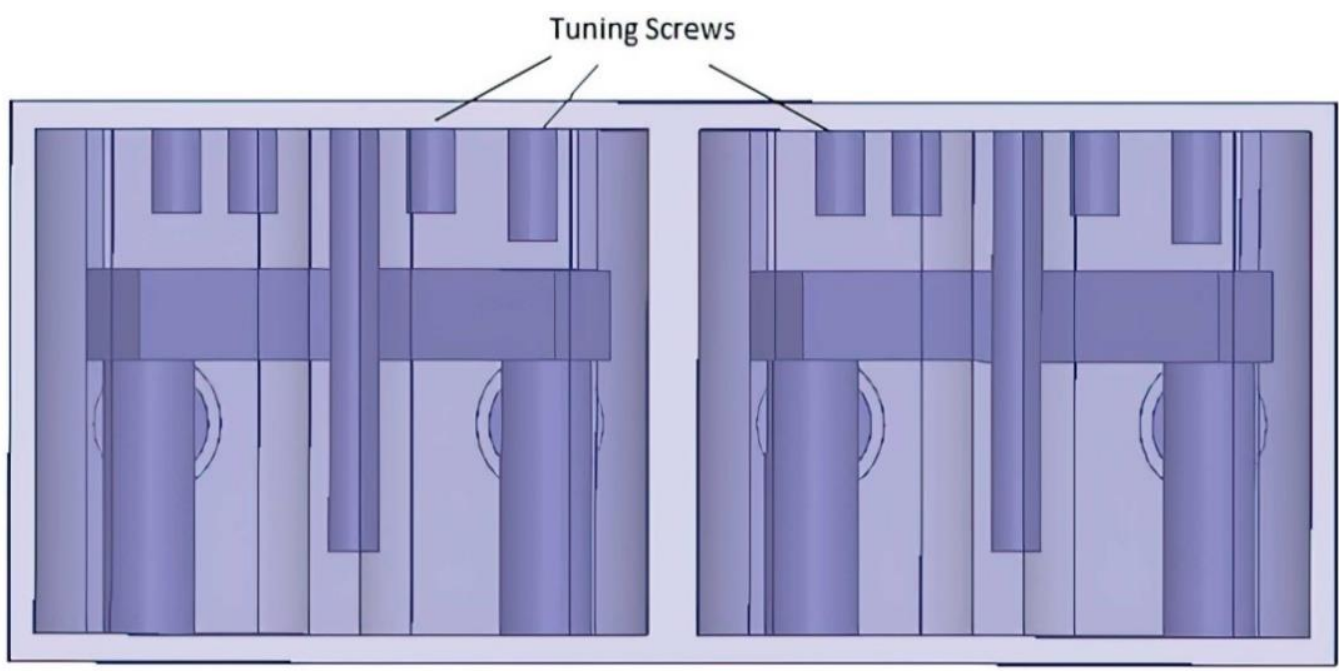

Figure 9. Proposed quadruple-mode band pass filter including tap feeders.

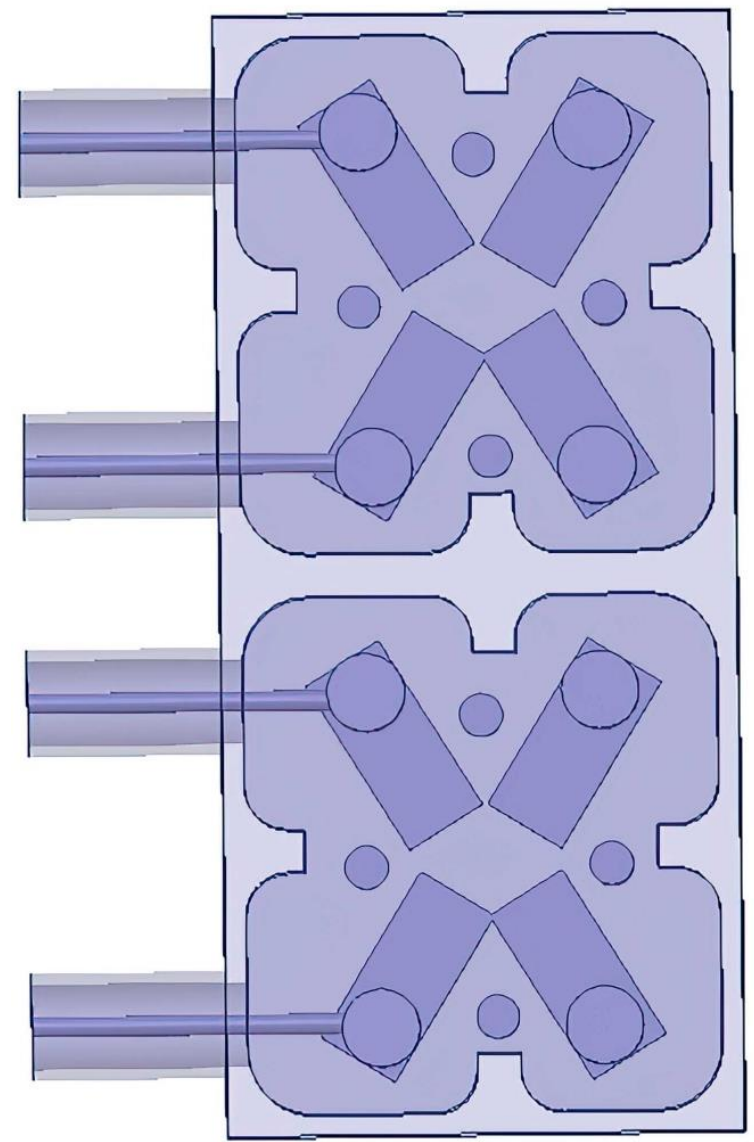

Figure 10. Design model of eight-pole bandpass resonating cavity filter by cascading two quadruplemode resonators. 
By considering two combline cavity resonators of diverse sizes with similar resonator rods magnetically coupled to an iris in the common wall. Hence, it does not produce a synchronous resonance condition to set the tuner heights equal to other.

A synchronously tuned state can be achieved by keeping tuning screw heights (say, Th1) constant and iteratively changing the other tuning screw height dimension (say, Th2) until a minimum value is reached by the different to two individual frequencies of the entire structure. An eight-pole bandpass filter by cascading two quadrature mode cavity filters is also designed for future work.

The quadrature mode cavity filter can be used as an elementary building block to create higher order resonating filters with different responses. The four-pole single cavity filter has been designed, the square with an outer-width $=26 \mathrm{~mm}$ side length and an outerlength $=20 \mathrm{~mm}$ height. These tuning screws used suffers small changes to compensate for manufacturing tolerances. The calculated centre frequency of the filter is $4.250 \mathrm{GHz}$, with a bandwidth of $850 \mathrm{MHz}$. The configuration of the filter model is developed in the HFSS. A simulation approach is used to model the entire design process of the cavity.

\section{Results}

Return loss compares the power reflected to the power fed from the transmission line. It also expresses the mismatch of the signal. Comparative analysis of measured and simulated return loss has been performed which shows resonating frequency at $4.250 \mathrm{GHz}$ produces measured maximum return loss of $-26 \mathrm{~dB}$ and simulated return loss of $-32 \mathrm{~dB}$ as shown in Figure 11.

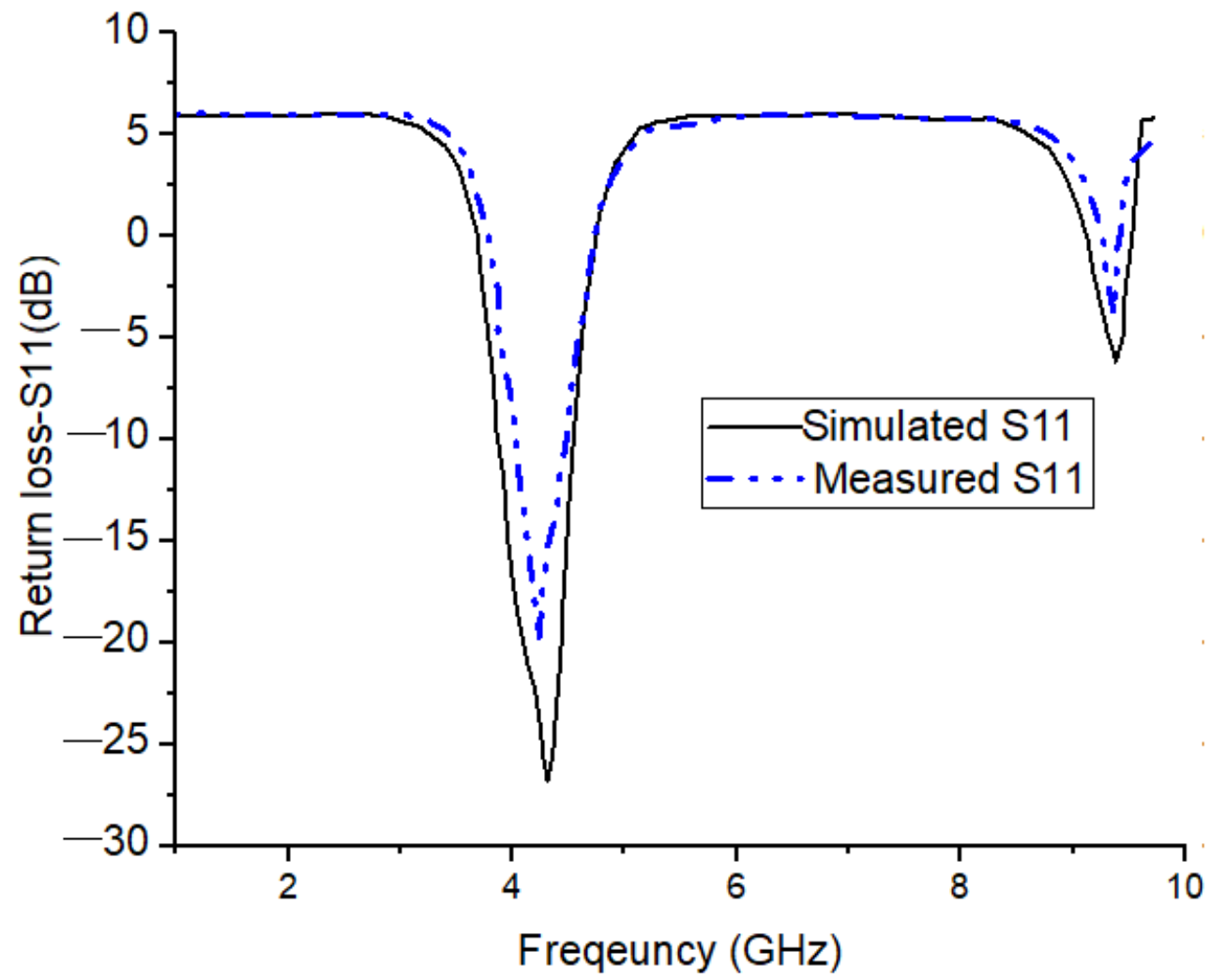

Figure 11. Comparative analysis of measured and simulated return loss of resonance cavity resonator.

Insertion loss is nothing but a loss of signal energy/power from the transmission line and its usually represented in decibels $(\mathrm{dB})$. In the S-parameter plot, it is upper portion of S21 plot where it touches $0 \mathrm{~dB}$ or near to $0 \mathrm{~dB}$. As much near to $0 \mathrm{~dB}$, shows less amount of insertion losses as shown in Figure 12. 


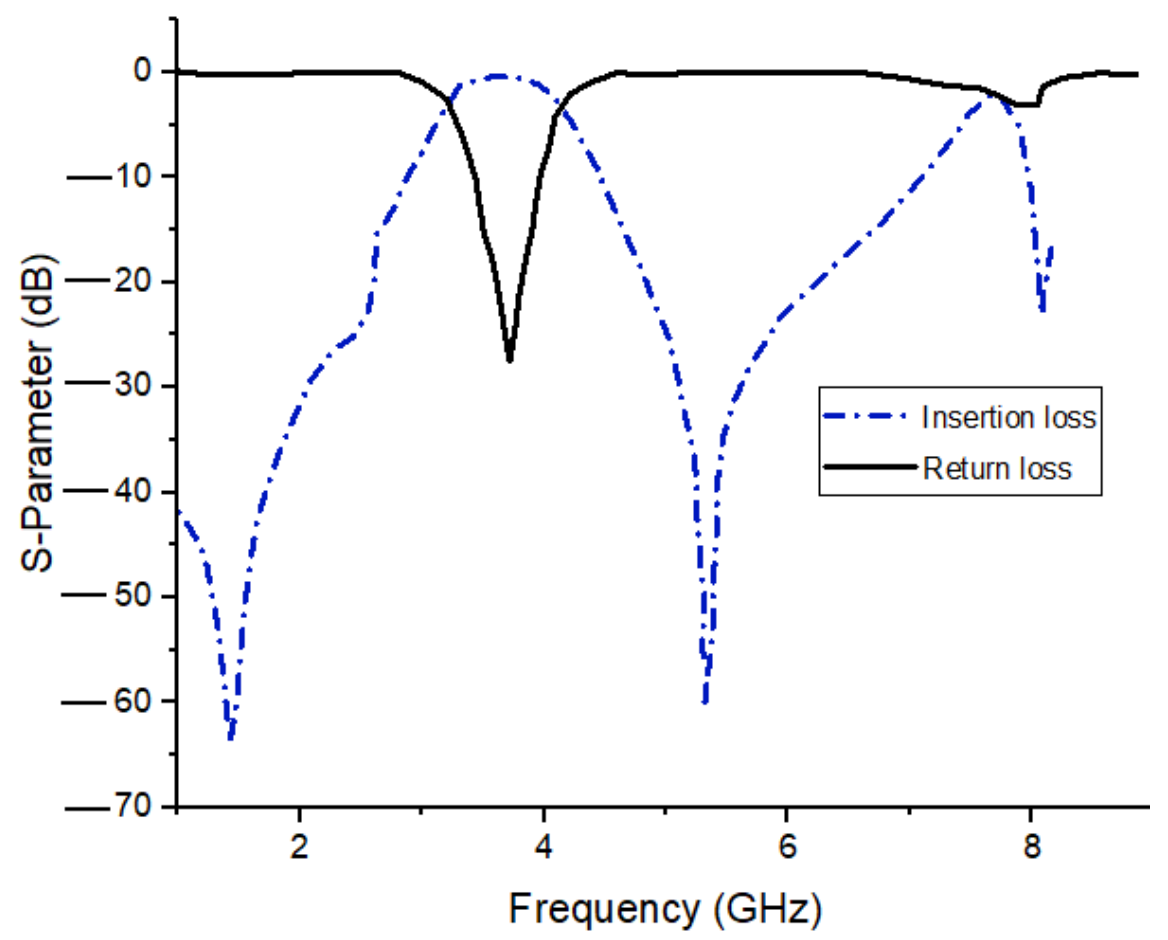

Figure 12. Insertion loss of cavity resonator.

The measured center frequency of the cavity resonator at $4.250 \mathrm{GHz}$, and the pass band bandwidth is $850 \mathrm{MHz}$. Table 2 shows the comparative analysis of quality factor of conventional and proposed quadrature mode bandpass filter.

Table 2. Comparative analysis of the conventional and proposed multimode resonating filters.

\begin{tabular}{|c|c|c|c|c|c|c|c|}
\hline Filter Type & Volume $\left(\mathrm{mm}^{3}\right)$ & $\begin{array}{c}\text { Quality } \\
\text { Factor, Q }\end{array}$ & $\begin{array}{c}\text { Bandwidth, } \\
\text { BW }\end{array}$ & $\begin{array}{l}\text { Resonant } \\
\text { Frequency }\end{array}$ & $\begin{array}{c}\text { Return Loss } \\
\text { (dB) }\end{array}$ & $\begin{array}{l}\text { Insertion } \\
\text { Loss (dB) }\end{array}$ & $\begin{array}{c}\text { Transmission } \\
\text { Zeros }\end{array}$ \\
\hline $\begin{array}{c}\text { Conventional } \\
\text { quadruple mode } \\
\text { BPF [25] }\end{array}$ & $\begin{array}{c}18,513 \\
(33 \mathrm{~mm} \times 33 \mathrm{~mm} \\
\times 17 \mathrm{~mm})\end{array}$ & 0.865 & $600 \mathrm{MHz}$ & $2566.8 \mathrm{MHz}$ & -20 & -32 & 2 \\
\hline $\begin{array}{c}\text { Two-pole } \\
\text { quadruple mode } \\
\text { BPF [26] }\end{array}$ & $\begin{array}{c}14510 \\
(26 \mathrm{~mm} \times 26 \mathrm{~mm} \\
\times 20 \mathrm{~mm})\end{array}$ & 2.1 & $850 \mathrm{MHz}$ & $4250 \mathrm{MHz}$ & $\geq-12$ & -42 & 2 \\
\hline $\begin{array}{c}\text { Compact } \\
\text { quad-mode } \\
\text { bandpass filter [27] }\end{array}$ & $\begin{array}{c}13,520 \\
(24 \mathrm{~mm} \times 24 \mathrm{~mm} \\
\times 20 \mathrm{~mm})\end{array}$ & 3.1 & $840 \mathrm{MHz}$ & $4350 \mathrm{MHz}$ & -27 & -35 & 4 \\
\hline $\begin{array}{l}\text { Proposed filter in } \\
\text { this paper } \\
\text { (four-pole } \\
\text { quadruple } \\
\text { mode BPF) }\end{array}$ & $\begin{array}{c}13,122 \\
(27 \mathrm{~mm} \times 27 \mathrm{~mm} \\
\times 18 \mathrm{~mm})\end{array}$ & 4.3 & $880 \mathrm{MHz}$ & $4250 \mathrm{MHz}$ & $\begin{array}{c}-32 \\
\text { (simulated) } \\
-26 \\
\text { (measured) }\end{array}$ & -62 & 4 \\
\hline
\end{tabular}

\section{Comparative Analysis of Conventional and Proposed Resonators}

Table 2 summarizes the filter characteristics of conventional and proposed quadruple mode bandpass filters. According to the results, the simulation results are extremely similar to the design specification. The slight frequency difference was caused by the external loading effect, which impacts the resonant frequencies and frequency ratio of the external linked resonators. The observed frequency response corresponds well to the simulation and design parameters. The presence of transmission zeros increases the filter's Quality factor of 4.3 at $4.2 \mathrm{GHz}$ which induces better selectivity and band pass characteristics. Figure 13 shows the fabricated prototype of proposed quadrature coupled resonating filter. From 
Table 2, the proposed four-pole quadruple mode BPF has lesser substrate height which results in better bandwidth of $880 \mathrm{MHz}$, for the resonating frequency of $4250 \mathrm{MHz}$. The tradeoff between bandwidth and Insertion loss to be monitored seriously for better filter characteristics, the proposed filter offers $-62 \mathrm{~dB}$ insertion loss against $880 \mathrm{MHz}$ which is better trade off ratio among the existing conventional filters. These satisfy the requirements of the design goals. The difference between simulation and measurement data is relatively tiny, and they accord very well. Some of these variations may be the result of machining faults and connectors with Sub-Miniature version A (SMA) pins.

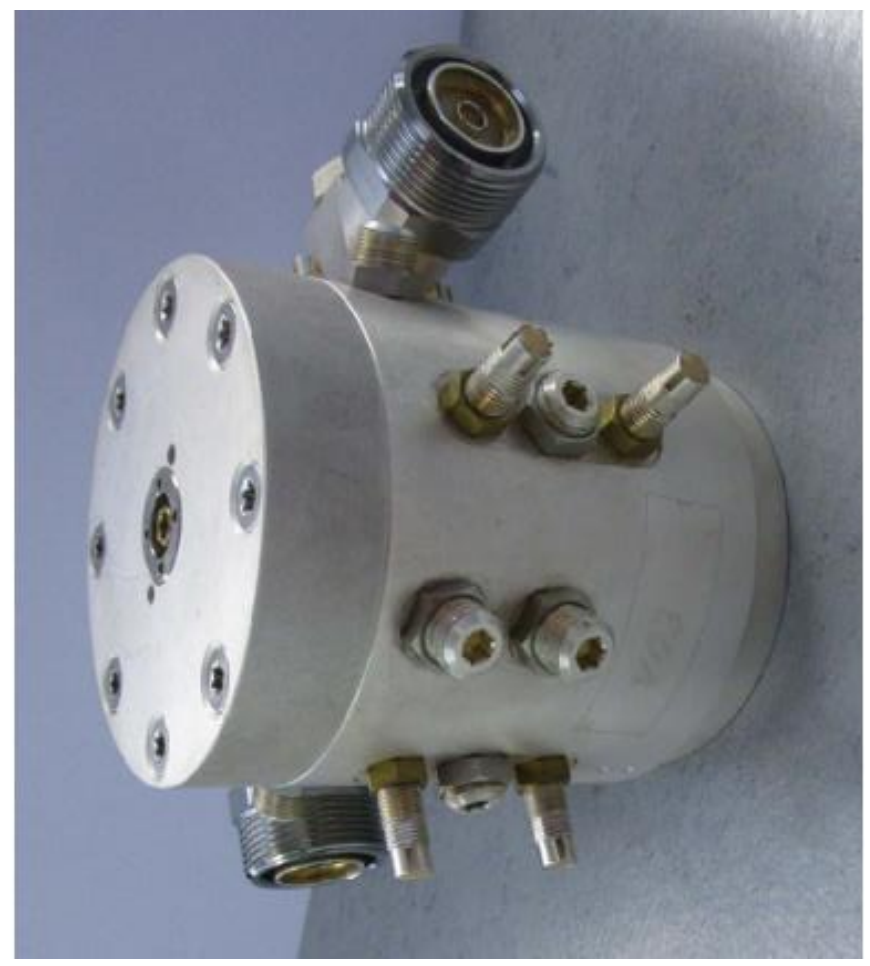

Figure 13. Fabricated prototype of proposed quadrature coupled resonating filter.

It is observed from the above comparative analysis that the simulated results are in good agreement which validates the designed concept. The performance comparison of the proposed four-pole quadruple mode bandpass filter with some other conventional combline filter for the next generation of wireless technology indicates that there is vast improvement in the bandwidth characteristics and selectivity. It is clear from the simulated results that the proposed filter has a small size and much higher bandwidth compared to other existing works.

\section{Conclusions}

The developed Quad-mode pass filters have 4 conductive posts inside a single cavity which have no metal walls within the cavity for new resonant characteristics and high utilization for 5G mid-band applications. In addition, the proposed resonator will give four versatile controllers. Transmission of zeros by of multiple cross-coupling occurring inside the resonating cavity. The mathematical model also emphasizes the ability to control the resonance frequencies of the conductive posts. As a result, the $5 \mathrm{G}$ sub-band (3.7-4.2 GHz) may be perfectly covered with a nearly flat passband. Over the desired bandwidth, a fractional bandwidth of $12.8 \%$ (500 MHz impedance bandwidth) was attained at the resonance frequency with a return loss of more than $18 \mathrm{~dB}$ and an insertion loss of less than $2.5 \mathrm{~dB}$. Four-pole resonating cavity filters have been developed and the centre frequency is $4.5 \mathrm{GHz}$. Insert loss at $0 \mathrm{~dB}$ and estimated bandwidth at $850 \mathrm{MHz}$ and Quality factor of 4.3. Co-efficient of reflection at 0 and return loss at $-23 \mathrm{~dB}$. The proposed design is appealing and ensures that low cost, 
better insertion loss, better bandwidth and quality factor and substantially miniaturized filters for wireless base station applications are achieved for 5G mid-band applications.

Author Contributions: Conceptualization: S.P.; methodology: S.P.; validation: B.T., S.A. and O.I.K.; formal analysis: Y.A., and S.P.; investigation: O.I.K. and Y.A; resources: O.I.K., S.A. and Y.A.; data curation: S.P. and B.T.; writing—original draft preparation: S.P. and: O.I.K.; writing-review and editing: Y.A. and O.I.K.; visualization: S.P. and Y.A.; supervision: B.T., Y.A., S.A. and O.I.K.; project administration: S.P., Y.A. and S.A.; funding acquisition: S.A. All authors have read and agreed to the published version of the manuscript.

Funding: This research is funded by Taif University, TURSP-2020/313.

Data Availability Statement: The study did not report any data.

Acknowledgments: We deeply acknowledge Taif University for supporting this study through Taif University Researchers Supporting Project Number (TURSP-2020/313), Taif University, Taif, Saudi Arabia.

Conflicts of Interest: The authors declare no conflict of interest.

\section{References}

1. Hameed, M.; Xiao, G.; Qiu, L.; Xiong, C.; Hameed, T. Multiple-Mode Wideband Bandpass Filter Using Split Ring Resonators in a Rectangular Waveguide Cavity. Electronics 2018, 7, 356. [CrossRef]

2. Basavarajappa, G.; Mansour, R.R. A high-Q quadruple-mode rectangular waveguide resonator. IEEE Microw. Wirel. Compon. Lett. 2019, 29, 324-326. [CrossRef]

3. Campanella, H.; Qian, Y.; Romero, C.O.; Wong, J.S.; Giner, J.; Kumar, R. Monolithic Multiband MEMS RF Front-End Module for 5G Mobile. J. Microelectromechanical Syst. 2021, 30, 72-80. [CrossRef]

4. Sardi, A.; Alkurt, F.Ö.; Özkaner, V.; Karaaslan, M.; Ünal, E.; Mohamed, T. Investigation of microwave power limiter for In-dustrial Scientific Medical band (ISM) applications. Int. J. RF Microw. Comput.-Aided Eng. 2020, 30, e22180. [CrossRef]

5. Watanabe, A.O.; Ali, M.; Sayeed, S.Y.B.; Tummala, R.R.; Pulugurtha, M.R. A Review of 5G Front-End Systems Package Integration. IEEE Trans. Compon. Packag. Manuf. Technol. 2021, 11, 118-133. [CrossRef]

6. Mahmud, R.; Awl, H.N.; Abdulkarim, Y.I.; Karaaslan, M.; Lancaster, M.J. Filtering two-element waveguide antenna array based on solely resonators. AEU-Int. Electron. Commun. 2020, 121, 153232. [CrossRef]

7. Nivethitha, T.; Palanisamy, S.K.; Prakash, K.M.; Jeevitha, K. Comparative study of ANN and fuzzy classifier for forecasting electrical activity of heart to diagnose Covid-19. Mater. Today Proc. 2021, 45, 2293-2305. [CrossRef]

8. Alotaibi, Y.; Almagrabi, A.O.; Alsufyani, A.; Alghamdi, S.A.; Alsufyani, N. Emerging recent innovative technologies based on sustainable business models for logistics 4.0. Soft Comput. 2021. accepted.

9. Alsufyani, A.; Alotaibi, Y.; Almagrabi, A.O.; Alghamdi, S.A.; Alsufyani, N. Optimized intelligent data management framework for a cyber-physical system for computational applications. Complex Intell. Syst. 2021, 1-13. [CrossRef]

10. Veeraiah, N.; Khalaf, O.I.; Prasad, C.V.P.R.; Alotaibi, Y.; Alsufyani, A.; Alghamdi, S.A.; Alsufyani, N. Trust Aware Secure Energy Efficient Hybrid Protocol for MANET. IEEE Access 2021, 9, 120996-121005. [CrossRef]

11. Alotaibi, Y.; Malik, M.N.; Khan, H.H.; Batool, A.; Islam, S.U.; Alsufyani, A.; Alghamdi, S. Suggestion Mining from Opinionated Text of Big Social Media Data. Comput. Mater. Contin. 2021, 68, 3323-3338. [CrossRef]

12. Zhang, X.Y.; Chen, J.-X.; Xue, Q.; Li, S.-M. Dual-Band Bandpass Filters Using Stub-Loaded Resonators. IEEE Microw. Wirel. Compon. Lett. 2007, 17, 583-585. [CrossRef]

13. Suryanarayana, G.; Chandran, K.; Khalaf, O.I.; Alotaibi, Y.; Alsufyani, A.; Alghamdi, S.A. Accurate Magnetic Resonance Image Super-Resolution Using Deep Networks and Gaussian Filtering in the Stationary Wavelet Domain. IEEE Access 2021, 9 , 71406-71417. [CrossRef]

14. Li, G.; Liu, F.; Sharma, A.; Khalaf, O.I.; Alotaibi, Y.; Alsufyani, A.; Alghamdi, S. Research on the Natural Language Recognition Method Based on Cluster Analysis Using Neural Network. Math. Probl. Eng. 2021, 2021, 9982305. [CrossRef]

15. Alotaibi, Y. A New Database Intrusion Detection Approach Based on Hybrid Meta-heuristics. CMC-Comput. Mater. Contin. 2021, 66, 1879-1895. [CrossRef]

16. Bharany, S.; Sharma, S.; Badotra, S.; Khalaf, O.I.; Alotaibi, Y.; Alghamdi, S.; Alassery, F. Energy-Efficient Clustering Scheme for Flying Ad-Hoc Networks Using an Optimized LEACH Protocol. Energies 2021, 14, 6016. [CrossRef]

17. Palanisamy, S.; Thangaraju, B.; Khalaf, O.I.; Alotaibi, Y.; Alghamdi, S.; Alassery, F. A Novel Approach of Design and Analysis of a Hexagonal Fractal Antenna Array (HFAA) for Next-Generation Wireless Communication. Energies 2021, 14, 6204. [CrossRef]

18. Luo, S.; Zhu, L. A Novel Dual-Mode Dual-Band Bandpass Filter Based on a Single Ring Resonator. IEEE Microw. Wirel. Compon. Lett. 2009, 19, 497-499.

19. Li, Y.C.; Wong, H.; Xue, Q. Dual-Mode Dual-Band Bandpass Filter Based on a Stub-Loaded Patch Resonator. IEEE Microw. Wirel. Compon. Lett. 2011, 21, 525-527. [CrossRef]

20. Bagci, F.; Fernández-Prieto, A.; Lujambio, A.; Martel, J.; Bernal, J.; Medina, F. Compact balanced dualband bandpass filter based on modified cou-pled-embedded resonators. IEEE Microw. Wireless Compon. Lett. 2017, 27, 31-33. [CrossRef] 
21. Alotaibi, Y. Automated Business Process Modelling for Analyzing Sustainable System Requirements Engineering. In Proceedings of the 2020 6th International Conference on Information Management (ICIM) IEEE, London, UK, 27-29 March 2020; pp. 157-161.

22. Jha, N.; Prashar, D.; Khalaf, O.I.; Alotaibi, Y.; Alsufyani, A.; Alghamdi, S. Blockchain Based Crop Insurance: A Decentralized Insurance System for Modernization of Indian Farmers. Sustainability 2021, 13, 8921. [CrossRef]

23. Nam, S.; Lee, B.; Kwak, C.; Lee, J. A New Class of K-Band High-Q Frequency-Tunable Circular Cavity Filter. IEEE Trans. Microw. Theory Tech. 2017, 66, 1228-1237. [CrossRef]

24. Subramanyam, A.V.G.; Sivareddy, D.; Krishna, V.V.; Srinivasan, V.V.; Mehta, Y. Compact Iris-Coupled Evanescent-Mode Filter for Spacecraft S-Band Data Transmitters. In Proceedings of the IEEE International Microwave and RF Conference (IMaRC), Hyderabad, India, 10-12 December 2015.

25. Wibisono, G.; Firmansyah, T.; Herudin, H.; Wildan, M.; Supriyanto, T.; Alaydrus, M.; Ujang, F. Multi wideband Bandpass Filter Based on Folded Quad Cross-Stub Stepped Impedance Resonator. Int. J. Antennas Propag. 2020, 2020, 4124721. [CrossRef]

26. Al-Yasir, Y.I.A.; Parchin, N.O.; Abdulkhaleq, A.M.; Bakr, M.S.; Abd-Alhameed, R.A. A Survey of Differential-Fed Microstrip Bandpass Filters: Recent Techniques and Challenges. Sensors 2020, 20, 2356. [CrossRef]

27. Wang, X.; Jang, G.; Lee, B.; Park, N. Compact Quad-Mode Bandpass Filter Using Modified Coaxial Cavity Resonator with Improved Q-Factor. IEEE Trans. Microw. Theory Tech. 2015, 63, 965-975. [CrossRef]

28. Yassini, B.; Yu, M.; Keats, B. A Ka-Band Fully Tunable Cavity Filter. IEEE Trans. Microw. Theory Tech. 2012, 60, 4002-4012. [CrossRef]

29. Kumar, P.S.; Jeevitha; Manikanda. Diagnosing COVID-19 Virus in the Cardiovascular System Using ANN. In Artificial Intelligence for COVID-19; Oliva, D., Hassan, S.A., Mohamed, A., Eds.; Studies in Systems, Decision and Control; Springer: Cham, Switzerland, 2021; Volume 358, pp. 63-75. [CrossRef]

30. Kumar, P.S.; Valarmathy, S. Development of a novel algorithm for SVMBDT fingerprint classifier based on clustering approach. In Proceedings of the IEEE-International Conference On Advances In Engineering, Science And Management (ICAESM-2012), Nagapattinam, India, 30-31 March 2012; pp. 256-261.

31. Wang, P.; Li, L.; Wei, S. Design of a tunable S-band narrow-band coaxial cavity filter. In Proceedings of the 2012 IEEE International Conference on Microwave and Millimeter Wave Technology (ICMMT), Shenzhen, China, 5-8 May 2012.

32. Wang, Y.; Yu, M. True Inline Cross-Coupled Coaxial Cavity Filters. IEEE Trans. Microw. Theory Tech. 2009, 57, $2958-2965$. [CrossRef]

33. Du, X.; Tang, P.; Chen, B. Design of a C-band coaxial cavity band pass filter. In Proceedings of the PIERS, Guangzhou, China, 25-28 August 2014; pp. 1065-1068. Available online: https:/ / www.piers.org/pierspublications/PIERS2014GuangzhouProceedings0 2.pdf (accessed on 9 September 2021).

34. Zhan, Y.; Chen, J.-X.; Qin, W.; Li, J.; Bao, Z.-H. Spurious-Free Differential Bandpass Filter Using Hybrid Dielectric and Coaxial Resonators. IEEE Microw. Wirel. Compon. Lett. 2016, 26, 574-576. [CrossRef]

35. Kurudere, S.; Erturk, V.B. Novel Microstrip Fed Mechanically Tunable Combline Cavity Filter. IEEE Microw. Wirel. Compon. Lett. 2013, 23, 578-580. [CrossRef]

36. Yuceer, M. A Reconfigurable Microwave Combline Filter. IEEE Trans. Circuits Syst. II Express Briefs 2015, 63, 84-88. [CrossRef] 